\title{
A LADY OF QUALITY IN SURINAME
}

\author{
Herinneringen eEner OfFiciersvrouw 1)
}

DOOR

\section{W. R. MENKMAN}

Tien weken na haar huwelijk met den luitenant Jan Felix Adriaan Eugeen van Lansberge vertrok de schrijfster, destijds een jonge vrouw van vijf en twintig jaar, naar Suriname, waar de vader van haar echtgenoot gouverneur was.

De wittebroodsweken had men voor een deel doorgebracht op Huize De Kolk onder Sint Oedenrode, bij de moeder van den gouverneur, Maria Margaretha Henrica van Oldenbarneveld genaamd Tullingh (1774-1864).

Omstreeks 1 Augustus 1862 werd de reis aanvaard, van het Nieuwe Diep, met het barkschip Carolina. Te voren was Jan naar Harderwijk getrokken, om een detachement van honderd man af te halen, dat onder zijn bevel den overtocht naar Suriname maken zou.

Niet onvermakelijk is de beschrijving van het van boord gaan der vrouw van den kapitein, met een karbies vol scheepsprovisie, van het uitreiken van oorlam aan de manschappen en de toespraak daarbij van den gezagvoerder, die blijkbaar ook zelf de afscheids-jenever niet versmaad had.

De reis was tamelijk voorspoedig (een week of vijf), maar vervelend; de Van Lansberges waren de eenige kajuitspassagiers, Kapitein Cupido was niet bepaald zijn gezelschap waard en een medicus voer niet mee. De soldaten vermaakten zich met zang en dans (orgel en harmonica) en kort voor aankomst werd de verjaardag van Kroonprins Willem (4 September) gevierd met een parade (parodie) en een tooneelvoorstelling. Er was bij het

1) De mémoires zijn van Mevrouw Wilhelmina Susanna Petronella Adriana van Lansberge, geb. Maas Geesteranus (1836-1914), welwillend ter beschikking gesteld door den Heer J. W. G. van Lansberge te 's Gravenhage. 
detachement een onderofficier ingedeeld, de latere Kapitein Theunis van het Surinaamsche garnizoen.

Bij de aankomst ter reede van Paramaribo lag aldaar $\mathrm{Zr}$ Ms schroefstoomschip Amstel; de gouverneur kwam aan boord in een achtriems tentboot, waarvan de bemanning uitgedost was met roode mutsen en Ned.vlaggen als gordels.

Ten gouvernements huize werd men verwelkomd door schoonmama Van Lansberge (Victoria Maria Rodrigues, de Colombiaansche echtgenoote van den gouverneur), die haar zorgen aan het jonge paar zou wijden, totdat dit een eigen woning (het logeergebouw) zou kunnen betrekken. Aan tafel werd men bediend door drie negers en twee Chineezen; op het erf van het gouvernements huis werkten vier slavinnen als waschvrouwen, luisterend naar de namen Première, Aspasia, Juno en Minerva.

Onze schrijfster vermeldt de komst, volgens haar in 1863, eener versterking der zeemacht, in verband met de aanstaande slavenemancipatie; de „Zoutman” echter kwam volgens het Kol. Verlsag reeds in 1862 uit Nederland aan, zoodat op het einde van dat jaar in Suriname aanwezig waren een oorlogsstoomschip en twee oorlogsschoeners.

Ook de expeditie tegen de wegloopers aan de Surnauskreek had plaats in het laatst van 1862, niet in 1863. De bedoeling zal inderdaad wel geweest zijn de weggeloopen slaven over te halen tot terugkeer naar hun meesters, die dan de schadevergoeding wegens de vrijverklaring niet zouden behoeven te ontberen. Dat er op deze expeditie een marine-officier gesneuveld zou zijn, vermeldt het Kol. Verslag niet, wel dat er in 1862 een officier der landmacht overleed ${ }^{1}$ ).

Zooals bekend is verliep de emancipatie over het algemeen rustig en ook Mevr. Van L. brengt in verband hiermede hulde aan de Herrnhutter leeraren. De schrijfster erkent dat aanvankelijk vele geëmancipeerden werkcontracten sloten tegen het officieel vastgestelde dagloon van $80 \mathrm{c}$. voor de mannen en $60 \mathrm{c}$. voor de vrouwen, met vrije woning en geneeskundige verzorging op de plantages.

Het jonge paar Van L. leidde blijkbaar een vroolijk bestaan; veel gezellige omgang met vrienden, picnics en logeerpartijtjes op plantages. Als adjudant van zijn vader had Jan een niet zwaren, maar wel met zijn levenslustigen aard strookenden

1) De gezondheidstoestand der troepen was, volgens het verslag, in 1862 zeer gunstig, d.w.z. dat er 22 man overleden, 4 sneuvelden en 4 verdronken. 
dienst. In 1867 maakte hij deel uit van de commissie welke tot taak had eenige moeilijkheden in de vestiging van Kappler aan de Marowijne uit den weg te ruimen. Een benoeming tot districtcommissaris was hem ontgaan, omdat zijn moeder, die blijkbaar mee bestuurde, het van belang achtte den schijn van bevoorrechting te vermijden.

In 1867 moest men afscheid nemen van papa Van Lansberge, die op 63 jarigen leeftijd aftrad als gouverneur en vervangen werd door W. H. J. van Idsinga, gewezen gouverneur ter Kuste van Guiné, daarvóór gezaghebber van Sint Eustatius en Saba. Ook onder den nieuwen bewindsman gelukte het den nu omstreeks dertigjarigen eersten luitenant Van L. niet een burgerbetrekking in Suriname te bemachtigen.

In 1869 ging zijn vrouw, alleen vergezeld van de kinderen en een nènè, naar Holland, ook thans met een schip dat geen medicus aan boord had, maar wel de vrouw van den kapitein, die Mevr. van L. weinig beviel. De gezagvoerder zelf was een wonderlijk type; hij viel flauw toen een tusschendeks-passagier, een maréchaussée, aan disenterie kwam te overlijden. Een der kinderen en de kindermeid werden ziek, een ander kind viel zich een gat in het hoofd en tot overmaat van rampen werd men op den vier en dertigsten dag der reis door zwaar stormweer beloopen. Waarop dan nog een oponthoud van veertien dagen in het Kanaal volgde, wegens windstilte en mist.

Eindelijk aankomst in het Nieuwediep, waar twee broers van onze reizigster het gezelschap in ontvangst namen, maar, zooals zij schrijft, meer belangstelling aan den dag legden voor de zwarte nènè dan voor haar. De winter werd doorgebracht in Den Haag, bij vader en moeder Maas Geesteranus.

In den zomer van 1870 aanvaardde het gezin de terugreis naar Suriname. In het hotel Den Burg te Nieuwediep, waar men eenigen tijd gelogeerd had, omdat er op gunstigen wind gewacht moest worden, trof men aan de table d'hôte het tooneelgezelschap van Judels aan en vernam men van het uitbreken van den Fransch-Duitschen oorlog.

Ditmaal trof het reisgezelschap het met het schip, den kapitein en het weer. Medepassagiers waren drie Herrnhutters, een echtpaar en een Fräulein die in Suriname haar toekomstigen man zou ontmoeten, verder een zwarte muziekmeester.

Bij aankomst te Paramaribo kon Mevr. van L. haar man alvast de kapiteins-fouragères overhandigen, want zijn promotie was op komst. 
Met een volgende gelegenheid arriveerde de jongste broeder Maas Geesteranus, die op een plantage geplaatst werd, maar met wien het niet bijzonder goed schijnt gegaan te zijn.

Kapitein Van Lansberge, nu garnizoenscommandant, vierde van hartelust zijn liefde bot voor muziek en voor bloemen; in het fort werd een prachtige bloementuin aangelegd. Overigens leidde men weer een leventje van vroolijken Frans, totdat het doodsbericht van den ouden Heer Maas Geesteranus ${ }^{1}$ ) zijn dochter in rouw dompelde; broeder Arnold ging nu meteen maar weer naar Holland terug.

Onder het jaartal 1872 spreekt Mevr. Van L. over de expedities van haar man met Cateau van Rosevelt, waarvan er een beschreven werd in den XXVII sten jaargang van dit tijdschrift; toen eindelijk de kaart van Suriname gereed was, kende de regeering in Nederland aan de beide explorateurs te zamen een bedrag van vier en twintig duizend gulden toe, niet als betaling (alle twee waren zij in overheids dienst), doch als blijk van waardeering voor hun werk. Deze gratificatie schijnt echter nimmer uitbetaald te zijn.

Als werkverschaffing aan de 2de klasse van discipline van het garnizoen werd in hetzelfde jaar 1872 een deel van het gouvernementsplein achter het fort Zeelandia tot park ingericht, waarin later de Buitensociëteit gevestigd werd.

Het jaar 1873 bracht de doodstijding van den oud-gouverneur Van Lansberge, terwijl er hetzelfde jaar in het Paramaribosche gezin een tweeling geboren werd, waarvan er echter een weder heenging. De gouverneur Van Idsinga vertrok en werd vervangen door Jhr C. A. van Sypestein, een vriend van de familie Maas Geesteranus. De kapitein Van Lansberge ging met verlof naar Holland en nam zijn dochtertje mede, dat den leeftijd bereikt had om in Patria opgevoed te worden.

Van het verlof, dat voor een deel doorgebracht werd te Brussel, waar de broeder van onzen kapitein ( $\mathrm{Mr} \mathrm{J}$. W. van Lansberge, de latere gouverneur generaal van Nederlandsch Indië) destijds ons land als gezant vertegenwoordigde, werd niet ten volle gebruik gemaakt; op het eind van het jaar was het verkleinde gezin weder te Paramaribo vereenigd.

Er volgde nu een tijd van moeilijkheden, minder goede verstandhouding onder de officieren van het garnizoen en een niet

1) Mr. Adrianin Jan Cornelis M. G., Heer van Zuid Scharwoude, vice president der Arr. Rechtbank te Alkmaar (1805-1871) 
altijd welwillende gezindheid van den gouverneur tegenover de mannen (Cateau van Rosevelt en Van Lansberge) die zich onderscheidden op een terrein waarop Van Sypesteyn zelf zich eveneens bewogen had. Ook ging de gezondheidstoestand van Van L. achteruit.

Anno 1875 wordt de aankomst vermeld van Baron Schimmelpenninck van der Oye, als administrateur van Financiën, dien enkele hedendaagsche lezers zich wellicht nog herinneren, in zijn otium in de Gravenstraat. Dan, 1876, de tentoonstelling (in het Logegebouw) ter bevordering van nijverheid en landbouw, gevolgd door groote feesten.

De ,goudkoorts" deed Van I. nog eenmaal, in 1877, naar het binnenland trekken, om voor een ontginningsmaatschappij te exploreeren. Een tienjarig zoontje werd dit jaar naar Holland gezonden en het daarop volgende jaar repatrieerde de rest van het gezin; de nu bijkans veertigjarige kapitein Van L. had genoeg van Suriname, tenzij hij er als majoor terug zou kunnen komen.

De reis ging ditmaal met de Fransche mail en een medepassagier van Suriname was de Heer Rodrigues, dien wij ons nog als Portugeesch consul te Paramaribo herinneren. Via Georgetown, Port of Spain en Castries (ook later nog de route der Annexe Fort de France-Cayenne van de Cie Gén. Transatlantique) ging het naar Martinique, voor overscheping aan boord van de „Amérique”, die met 600 passagiers vertrekken zou, meest ruwe, vuile Amerikaansche Spanjaarden, schrijft Mevr. Van Lansberge; de Parijsche tentoonstelling was blijkbaar een groote attractie voor Latijnsch Amerika.

De reis was niet aangenaam; het eten was beneden peil en een twist tusschen twee Zuidamerikaansche medepassagiers eindigde met een moordaanslag en een zelfmoord. Tot verzet van de zenuwen, zegt de schrijfster, gaf de commandant denzelfden avond een bal, met champagne ,,à discrétion".

Een plezierige afwisseling was het aandoen van Fayal, waar versche proviand ingeslagen werd; Mevr. Van L. houdt de Azoren voor Spaansche eilanden.

Van Saint Nazaire reisde men via Angers naar Parijs, waar de tentoonstelling bezocht werd - en van daar naar Den Haag. Vroolijk was het verblijf in Holland niet; Van L. werd twee maal in een sanatorium te Laag Soeren verpleegd, zijn vrouw moest wegens een leveraandoening behandeld worden.

De bedoeling was dat de kapitein Van L., zonder gezin, naar Curaçao zou gaan, om aldaar zijn promotie tot majoor af te 
wachten. De benoeming van zijn zwager (geh. met Emilie van Lansberge) J. H. A. W. Baron van Heerdt tot Eversberg tot gouverneur van Curaçao, maakte de scheiding iets minder pijnlijk. Samen ging het echtpaar via Parijs naar Saint Nazaire, waar men afscheid nam, zooals zou blijken voor altijd.

Op Curaçao, als kapitein-commandant der troepen en van het garnizoen, overleed J. F. A. E. van Lansberge, na een maagbloeding, op 23 Januari 1883. Zijn overschot werd bijgezet in het familiegraf der familie Hellmund op Mundo Nobo; toen reeds de rustplaats van zijn zuster Charlotte (de in 1864 overleden Mevrouw Hellmund) en van zijn in Coro gesneuvelden broeder Henri.

Mevrouw Van Lansberge, die haar man ruim een en dertig jaar overleefd heeft, schreef haar „Herinneringen uit een veelbewogen leven" in het jaar waarin zij weduwe werd; zij droeg deze mémoires aan haar kinderen op. Er waren er in Suriname zes geboren, waarvan twee aldaar overleden waren.

Niet als historisch document heeft dit manuscript waarde, doch als document humain, dat ons iets leert van het leven in West Indië in een tijd welke thans wel heel lang achter ons lijkt te liggen. Ook vindt men er namen in terug, welke in de intieme Surinaamsche geschiedenis een plaats gevonden hebben, namen van militairen, ambtenaren, plantagehouders e.a., uit een tijdperk toen Paramaribo nog een typisch koloniaal-Hollandsch stadje was.

Mei 1947.

\section{$\mathrm{N}$ a schrift.}

De Angelsaksers, met hun voorliefde voor gedenkschriften, dagboeken enz., kunnen onder hun Westindische litteratuur wellicht wat meer door vrouwen nagelaten pennevruchten aanwijzen dan wij; en zij gaan ook gereeder tot de publicatie van zoodanige geschriften over. Geraldine Mozley gaf de Letters to Jane (I788-I796) from Jamaica uit (West India Committee 6 sh. 6 d.), Evangeline Walker Andrews en Chs McLean Andrews bezorgden de uitgave van Janet Schaw's reisverhaal, onder den titel Journal of a lady of quality. Being the Narrative of a Journey from Scotland to the West Indies, North Carolina and Portugal, in the years 1774 to 1776 (New Haven; Yale University Press 1921). Janet Schaw's manuscript wordt bewaard in 
eht Britsch Museum (Egerton 2423); van de schrijfster zelf lezen wij niet veel anders dan dat zij een Schotsche Presbyteriaansche was, die haar broeder vergezelde naar Saint Kitts, waar hij searcher of Customs worden zou, terwijl een andere broeder op een plantage in N.Carolina woonde.

Het kwam mij voor dat Mevrouw Van Lansberge-Maas Geesteranus, wat stand en relaties aangaat, zeker niet minder dan Miss Schaw een ,lady of quality" was, vandaar dat het mij behaagde haar denzelfden titel te geven dien de Amerikaansche professor en zijn vrouw voor de achttiende eeuwsche Schotsche reizigster gekozen hebben.

M. 